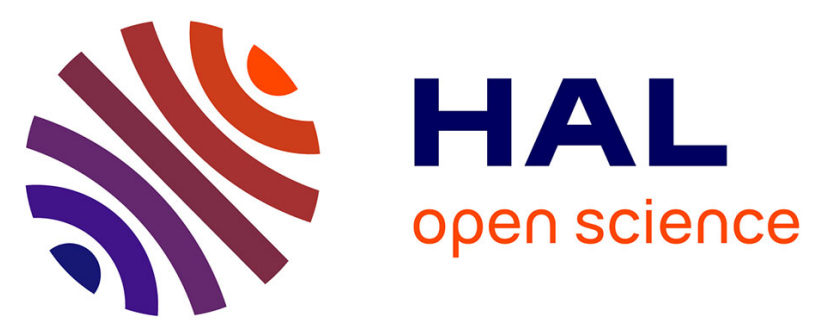

\title{
Sham tDCS: A hidden source of variability? Reflections for further blinded, controlled trials
}

Clara Fonteneau, Marine Mondino, Martijn Arns, Chris Baeken, Marom Bikson, Andre R. Brunoni, Matthew J. Burke, Tuomas Neuvonen, Frank Padberg, Alvaro Pascual-Leone, et al.

\section{To cite this version:}

Clara Fonteneau, Marine Mondino, Martijn Arns, Chris Baeken, Marom Bikson, et al.. Sham tDCS: A hidden source of variability? Reflections for further blinded, controlled trials. Brain Stimulation, 2019, 12, pp.668 - 673. 10.1016/j.brs.2018.12.977 . hal-03486525

\section{HAL Id: hal-03486525 \\ https://hal.science/hal-03486525}

Submitted on 20 Dec 2021

HAL is a multi-disciplinary open access archive for the deposit and dissemination of scientific research documents, whether they are published or not. The documents may come from teaching and research institutions in France or abroad, or from public or private research centers.
L'archive ouverte pluridisciplinaire HAL, est destinée au dépôt et à la diffusion de documents scientifiques de niveau recherche, publiés ou non, émanant des établissements d'enseignement et de recherche français ou étrangers, des laboratoires publics ou privés.

\section{(ㄷ)(1) $\$$}

Distributed under a Creative Commons Attribution - NonCommerciall 4.0 International 


\section{Title}

Sham tDCS: a hidden source of variability? Reflections for further blinded, controlled trials

\section{Authors}

Clara FONTENEAU ${ }^{1,2,3}$, Marine MONDINO ${ }^{1,2,3}$, Martijn ARNS ${ }^{4,5}$, Chris BAEKEN ${ }^{6,7,8}$, Marom BIKSON ${ }^{9}$, Andre R BRUNONI ${ }^{10,11}$, Matthew J BURKE ${ }^{12}$, Tuomas NEUVONEN ${ }^{13}$, Frank PADBERG ${ }^{10}$, Alvaro PASCUAL-LEONE ${ }^{12}$, Emmanuel POULET ${ }^{1,2,3}$, Giulio RUFFINI ${ }^{14}$, Emiliano SANTARNECCHI ${ }^{12}$, Anne SAUVAGET ${ }^{15,16}$, Klaus SCHELLHORN ${ }^{4}$, MarieFrançoise SUAUD-CHAGNY ${ }^{1,2,3}$, Ulrich PALM ${ }^{10}$, Jérome BRUNELIN ${ }^{1,2,3}$

\section{Affiliations}

1) INSERM U1028; CNRS UMR5292; Lyon Neuroscience Research Center, Psychiatric

Disorders: from Resistance to Response Team, F-69000, France

2) University Lyon 1, Villeurbanne, F-69000, France

3) Centre Hospitalier Le Vinatier, Lyon, F-69000, France

4) neuroCare Group GmbH, Munich, Germany

5) Research Institute Brainclinics, Nijmegen, The Netherlands

6) Department of Psychiatry and Medical Psychology, Ghent University Hospital, Ghent University, Ghent, Belgium

7) Department of Psychiatry, University Hospital UZBrussel, Brussels, Belgium

8) Ghent Experimental Psychiatry (GHEP) Lab, Ghent, Belgium 
9) Department of Biomedical Engineering, The City College of New York, New York City, New York, USA

10) Department of Psychiatry and Psychotherapy, University Hospital, LMU, Munich, Germany

11) Service of Interdisciplinary Neuromodulation (SIN), Laboratory of Neuroscience (LIM27)

and National Institute of Biomarkers in Neuropsychiatry (INBioN), Department and Institute of Psychiatry, University of São Paulo Medical School, São Paulo, Brazil.

12) Berenson-Allen Center for Noninvasive Brain Stimulation, Beth Israel Deaconess Medical Center and Harvard Medical School, Boston, MA

13) Sooma Oy, Kuortaneenkatu 2, 00510 Helsinki, Finland

14) Neuroelectrics Corporation, 210 Broadway, 02139 Cambridge, MA (USA)

15) CHU de Nantes, Psychiatric Neuromodulation Unit, Addictology and Liaison-Psychiatry Department, Nantes, France

16) Laboratory "Movement, Interactions, Performance" (E.A. 4334), Faculty of Sport Sciences, University of Nantes, Nantes, France

\section{Corresponding author:}

Jerome BRUNELIN

Centre Hospitalier Le Vinatier

Equipe de Recherche PSYR2 - CRNL

Pôle Est - Bâtiment 416 - 1er étage

BP 30039 - 95 boulevard Pinel

69678 BRON Cedex - FRANCE

Phone Number: +33(0)437915565 


\begin{abstract}
Transcranial direct current stimulation (tDCS) is a non-invasive brain stimulation technique increasingly used to modulate neural activity in the living brain. In order to establish the neurophysiological, cognitive or clinical effects of tDCS, most studies compare the effects of active tDCS to those observed with a sham tDCS intervention. In most cases, sham tDCS consists in delivering an active stimulation for a few seconds to mimic the sensations observed with active tDCS and keep participants blind to the intervention. However, to date, shamcontrolled tDCS studies yield inconsistent results, which might arise in part from sham inconsistencies. Indeed, a multiplicity of sham stimulation protocols is being used in the tDCS research field and might have different biological effects beyond the intended transient sensations. Here, we seek to enlighten the scientific community to this possible confounding factor in order to increase reproducibility of neurophysiological, cognitive and clinical tDCS studies.
\end{abstract}

\title{
Keywords
}

Transcranial direct current stimulation; sham; placebo; reproducibility; variability; tDCS 
Text

In light of increasing interest surrounding reproducible transcranial direct current stimulation (tDCS) studies, guidelines have emerged specifically pointing to the importance of blinding [13]. Blinding, or masking, is a cornerstone of randomized controlled trials and is especially challenging to be obtained for non-pharmacological interventions [4]. It consists of a set of procedures designed to keep participants (single blind procedure) and experimenters (double blind procedures) unaware of the administered intervention (active or sham) and thus avoid bias and unrelated observable effects. For subject blinding, the sham method most commonly used in tDCS studies is based on mimicking typical initial sensations of active tDCS underneath the electrode sites (e.g., tingling, itching). For experimenter blinding, allocation concealment is achieved by entering numeric codes [5] assigned to waveform arms (e.g. sham, active) or a toggle (A/B mode). In addition, some devices adjust an impedance display on the device screen that also mimics impedance changes expected in the "active" functioning of the device and detect loss of electrode contact [5].

Thus, sham procedures in non-invasive brain stimulation trials are fundamental due to the placebo response observed in non-invasive brain stimulation trials [6] and the fact that nonblinded trials overestimate the effects of subjective and objective outcomes [7]. However, the neurobiological effect of sham tDCS remains an under-addressed notion in the literature and can be subdivided into two types of effects: 1) the direct neurobiological effects, specifically the results of the type of sham used, in this case weak electrical currents; 2) the indirect neurobiological effects, that are seen across studies, e.g. general 'placebo/nocebo' or 'non- 
specific' effects. These would be independent of the type of sham used. With this in mind, as other interventional tools, sham tDCS has two important problematic and competing aspects.

Firstly, the blinding efficacy of current sham tDCS protocols is non-optimal and can be improved depending on blinding objectives [8-10], especially in cross-over studies. In this line, recent "active" sham protocols, based on modeling and leveraging multichannel tDCS, have been developed to mitigate the subject blinding problem $[11,12]$. For example, an approach could be to use multi-electrode montages, optimized to create skin sensations and effects while keeping cortical electric fields close to zero [11], using realistic head models and multichannel optimization algorithms [13]. This technique provides a way to control both objective and subjective sensation factors for double blinding in experiments and can be made even more precise when based on personalized realistic head modeling. Another possibility, put forward by recent studies $[14,15]$, is the use of topical pretreatments to reduce erythema and minimise paraesthesia in both the active and sham group. Therefore, if successful, this would render the "active" stimulation in the sham group unnecessary and the sham group would only control for indirect neurobiological effects. More generally, while current density in the skin is always higher than in the brain, the ratio can vary by several orders of magnitude depending on the montage [16]. Moreover, blinding of the experimenters could also be improved. Indeed, skin redness after tDCS was reported to affect the blinding efficacy [17]. Therefore, regardless of the protocol used, it is critical to systematically collect data assessing the quality of the blinding. This can be as simple as asking participants what they believe they received (sham or active) and their confidence in this assessment. We recommend scientists and clinicians use the standardized questionnaire validated and published recently by Antal and colleagues (2017) [18]. The 
documents can be downloaded from the website: http://www.neurologie.unigoettingen.de/downloads.html.

Secondly, sham tDCS might have biological effects beyond the intended transient sensations [19]. In most cases, sham tDCS consists in delivering a short period of active stimulation at the beginning of the stimulation session (e.g., $10 \mathrm{~s}$ at $0.1 \mathrm{~mA}$ [20], $120 \mathrm{~s}$ at $1 \mathrm{~mA}$ [21]) followed by no stimulation for a total duration equal to the duration of the active stimulation [22]. It is usually assumed that sham stimulation controls any potential effects unrelated to the direct cortical stimulation itself. Based on studies using tDCS and transcranial magnetic stimulation (TMS) over the motor cortex, sham stimulation is unlikely to produce lasting changes in cortical excitability after a single session [23]. However, several studies have investigated tDCS effects with parameters similar to those of sham parameters (i.e., short stimulation duration), with mixed findings [24-29]. Placebo-controlled studies report a differential effect of the sham stimulation, some reporting no effect of $30 \mathrm{~s}$ stimulation (15 s ramp-up to $2 \mathrm{~mA}, 15 \mathrm{~s}$ ramp-down [30]; $10 \mathrm{~s}$ ramp-up/down, $30 \mathrm{~s}$ stimulation at $1 \mathrm{~mA}$ [31]; $15 \mathrm{~s}$ ramp-up/down, $30 \mathrm{~s}$ stimulation at $2 \mathrm{~mA}$ [32]) while others finding an effect on different neurophysiological parameters (10 s ramp-up to $1 \mathrm{~mA}, 60 \mathrm{~s}$ ramp-down to $0.034 \mathrm{~mA}$ and continuous $13 \mathrm{~min} 50 \mathrm{~s}$ at $0.034 \mathrm{~mA}$ [33]; $30 \mathrm{~s}$ ramp-up to $2 \mathrm{~mA}, 30 \mathrm{~s}$ ramp-down, at the start and end of the stimulation [34]). One tDCS study investigating the neurobiological effects of parameters used in sham conditions as the primary objective reported that a single session of 15 min sham tDCS (i.e., $10 \mathrm{~s}$ ramp-up to $1 \mathrm{~mA}, 60 \mathrm{~s}$ ramp-down to $0.034 \mathrm{~mA}$ and continuous $13 \mathrm{~min} 50 \mathrm{~s}$ at $0.034 \mathrm{~mA}$ ) had similar effects to 1 or 2 $\mathrm{mA}$ of 15 min stimulation [33] and different than $0 \mathrm{~mA}$ stimulation on an event-related EEG component ( $\mathrm{P} 3$ amplitude). According to this study, although no behavioral effects were 
observed, a single session of "sham" intervention could exert neuromodulatory effects for some outcomes. Such a result could be explained by skin sensations intentionally produced in the sham arm (ramp up/down) or cortical modulation by the micro-ampere-scale current. The potential physiological effects of non-invasive micro-ampere-scale currents remain to be established, requiring effects at electric fields two orders of magnitude below those established effective in animal models [35-37]. This could be also related to the stochastic resonance model predicting that small amounts of noise injected into a system promote low-level signals leading to enhanced functions within this system [38-40]).

As with other therapeutic tools, the possible effects of sham tDCS itself could be enhanced when repeated sessions are delivered. Indeed, repeated-sessions of tDCS is a promising therapeutic intervention to decrease symptoms and improve cognition in neuropsychiatry. Some of the variability in study outcomes [22] might arise from sham inconsistencies. Indeed, since the first sham-controlled clinical study, numerous sham parameters have been described. For example, recent studies investigating the clinical impact of tDCS in patients with major depression were assessed from a systematic literature search using the following terms: ("tDCS" AND (“depression” OR “MDD”) AND (“2018” OR “2017”). From the 106 eligible studies identified in September 2018, we focused on the 4 randomized controlled trials (RCT) [41-44]. Interestingly, sham parameters of these studies differ (current was turned off automatically after $30 \mathrm{~s}$ of $2 \mathrm{~mA}$ stimulation [41]; $30 \mathrm{~s}$ of $0.5 \mathrm{~mA}$ stimulation [42]; ramp-up $30 \mathrm{~s} /$ ramp-down $15 \mathrm{~s}$, $30 \mathrm{~s}$ of $2 \mathrm{~mA}$ stimulation [43]; constant current of $0.034 \mathrm{~mA}+2$ ramps throughout sham intervention up to 1 and $0.5 \mathrm{~mA}$ (10 s ramp-up, $60 \mathrm{~s}$ ramp-down) [44]). Aside from this example from recent studies of tDCS in major depressive disorder, the use of different sham parameters in 
clinical studies reveals significant variations of the injected electric charge from 15 [42] to 109 [33] $\mathrm{mC}$. Another point to consider in these clinical studies is the potential impact of repeated low-intensity sham stimulations, which could produce behavioral changes in the control condition that confound detection of therapeutic responses to the active arm. Thus, sham methodology could be an important parameter among others (session duration, total number of session, number of sessions a day, duration between two sessions, current intensity, site of stimulation) in the design of tDCS clinical studies, not only for blinding, but also to investigate potential specific neuromodulatory effects linked to the sham stimulation itself.

Several sham protocols for tDCS have been reported in the literature (Figure 1). Based on a recent review [3], $84 \%$ of 173 studies report using similar approaches as reported in an early study by Gandiga et al. [45]. However, the original protocol (i.e., $10 \mathrm{~s}$ ramp-up followed by $30 \mathrm{~s}$ of active stimulation at $1 \mathrm{~mA}$ before manually turning off the stimulator, Figure 1A) has been modified, adjusting (1) the intensity and duration of active current being delivered (from "no current" to $2 \mathrm{~min}$ at $1 \mathrm{~mA}$ ), (2) the duration of ramp-in and ramp-out phases (e.g., 5-30 s), and (3) the number of ramps done throughout the stimulation. Indeed, a newer sham protocol proposed 2 periods of active stimulation, including ramps up/down with 10-30 s of stimulation in between, over the first and last seconds of the stimulation [46] (Figure 1B).

\section{INSERT FIGURE 1 ABOUT HERE}

In order to help practitioners deliver adequate and reproducible sham treatment interventions, several commercial stimulators include a 'double blind study mode', which delivers a built-in- 
sham mode. However, sham-placebo modes vary across stimulator brands, which could be a confounding factor when comparing studies and in multicenter studies using various devices across centers (Table 1). In addition, it should be noted that these sham parameters can also be adapted upon request to the companies.

\section{INSERT TABLE 1 ABOUT HERE}

Thus, we urge scientists and clinicians to be aware of the sham parameters they used and accurately report them in scientific literature, including when not using the preprogrammed builtin 'double blind study mode'. This is particularly critical for studies that use devices not designed for tDCS (e.g., iontophoresis devices such as the Intelec Advanced Therapy System, Chattanooga, USA).

With this in mind, we have detailed in Supplementary Material 1 the sham-controlled studies using bifrontal (F3/F4/FP1/FP2) and fronto-temporal montages (F3FP1/T3P3) based on recent major reviews $[22,47,48]$ and divided them depending on their sham parameters described (device "turned off", short stimulation) and looked the impact on their primary outcome. We report that out of 103 studies, only 14 studies do not report a short active stimulation (only ramps), 51 studies report using ramp-down before turning off the device and 44 studies report shutting off the device after the active stimulation. Of those 103 studies, 46 were excluded from further investigation due to missing information concerning the sham parameters used. With the remaining 57 studies, we were able to investigate if the total charge in the sham arm had an effect (Yes or No) on the primary outcome (Supplementary Material 2). From this analysis, the total charge delivered doesn't seem different when comparing studies showing no effect of active 
tDCS compared to sham tDCS $(\mathrm{n}=6 ; 94 \mathrm{mC}(+/-115))$, compared those showing an effect $(\mathrm{n}=51$; $73 \mathrm{mC}(+/-69))$. This should be taken with caution, as very few negative studies $(\mathrm{n}=6)$ could be analyzed. Thus, to date, no recommendation can be made regarding a specific sham protocol and none seem to be more rigorous than another. Further studies are needed to assess the direct and indirect effects of sham protocols.

Choosing the optimal control condition is another important issue to consider. The field has mainly focused on "active sham" control conditions mimicking stimulation sensations as realistically as possible. This approach has partly been chosen because "placebo" control conditions have been strongly criticized in TMS and drug research [49-53] and because "active sham" control conditions could improve the blinding effect. Remarkably, systematic assessment of blinding has been more often reported in brain stimulation trials compared to drug trials [54]. Moreover, control groups or waiting lists, used in psychotherapy and mindfulness research for example, do not allow true double-blind trials $[55,56]$. A final complicating factor is the growing body of research suggesting that control conditions themselves may be capable of meaningfully modulating relevant brain regions/networks [57]. Realistic and elaborate sham tDCS protocols could invoke strong therapeutic expectations and thus induce particularly large placebo effects. This relates to the notions of 'differential placebo effects', the concept that different types of placebos (e.g. inert pill versus sham device) may yield different magnitudes of placebo response [58-60]. This is a topic that has been studied for decades, but becomes paramount as sophisticated medical technologies require elaborate placebo controls to maintain blinding integrity. 
Thus, several promising research avenues can be put forward with regard to decreasing the influence of sham tDCS, with the main aim of keeping the balance between maintaining participant blinding and limiting the development of sham into an 'active control' condition. One the one hand, with the perspective of using tDCS in clinical settings, the use of an "active control", i.e. stimulating a region considered inactive with regard to the main question, as with TMS [61], could be recommended in some cases, however, with the risk of including an active control with unknown neurophysiological effects. Alternatively, the use of "active controls" based on realistic head modeling with multi-electrode montages exploiting scalp shunting mechanisms can be explored as discussed above [11]. On the other hand, sham tDCS conditions could also be reduced to a minimum of active components, even going as far as no active components, when using protocols with topical pretreatments [14,15]. Furthermore, new protocols could be developed in order to dectect the dissociation between direct and indirect neurobiological effects, as done in other research fields (e.g. neurofeedback, [62]).

In summary, the use of different sham stimulations can be a confounding factor in reconciling results across clinical, cognitive, and neurophysiological studies of tDCS. Indeed, when functional neuroimaging, at different spatial and temporal levels (biological, functional and structural) is used to gain new useful information for inferring the mechanisms of action of tDCS (e.g., [63,64]) conclusions are drawn based on comparison between active and sham interventions. Questions that should be further explored include whether certain modalities of sham tDCS have a neurobiological effect, and if so, which ones. In addition, the cumulative clinical effects of low-intensity, repeated sham tDCS should be further investigated, as a recent controlled trial suggested that it could have meaningful antidepressant effects [44]. Ultimately, more research is necessary to ascertain the direct neurobiological effects of sham tDCS protocols 
and evaluate their reliability [65, but see 66]. It should be underscored that simply "turning off" the tDCS device could harm blinding, therefore overestimating the signal of active stimulation. In addition, accurately reporting sham interventions is crucial to help increase reproducibility in the tDCS research field (sham should be reported with the same rigor as any stimulation dose; [67]). Future meta-analyses could also include investigating pre-post effect sizes of all sham conditions across studies (e.g. larger effect size for 'ramp-up-ramp-down' vs 'constant low intensity' shams?), as done in a recent meta-analysis looking specifically at the effects of sham tDCS on corticospinal excitability [68]. Nevertheless, in parallel to a reliable sham arm, other aspects should be considered in order to have reproducible tDCS studies, such as better training of practitioners and reporting of the electrode preparation (e.g. saline quantity, re-use, cleaning method...) and placement [2]. Our hope is that a better understanding of these neurobiological processes can decrease the noise in controlled trials, ultimately clarifying tDCS efficacy.

\section{Conflict of interest}

M.A. is a minority shareholder in neuroCare Group (Munich, Germany) and received research funding from neuroCare Group, and equipment support from Deymed, neuroConn, Brainsway and Magventure. M.B. is a shareholder in Soterix Medical Inc. The City University of New York has patents on brain stimulation with M.B. as inventor. A.R.B. is recipient of a CAPES/ Alexander von Humboldt fellowship award for experienced researchers and is a consultant from Neuroconn GmbH. The Laboratory of Neuroscience receives financial support from the Beneficent Association Alzira Denise Hertzog da Silva and the CAPES / INCT program "National Institute of Biomarkers in Psychiatry" (INBioN). T.N. is a shareholder at Sooma Oy. F.P. received research support from neuroConn GmbH, Ilmenau, Germany, and Brainsway Inc., 
Tel Aviv, Israel, as well as speaker's honorarium from Mag\&More GmbH, Munich, Germany, and neuroCare Group. G.R. is a shareholder and works for Neuroelectrics Corporation. K.S. is a shareholder and works for neuroCare Group GmbH. E.S. is supported by the BROAD Institute at Harvard-MIT (Boston, MA, USA) via 2016P000351, by the Defense Advanced Research Projects Agency (DARPA) via HR001117S0030, by the Beth Israel Deaconess Medical Center (BIDMC) via the Chief Academic Officer (CAO) grant 2017. E.S. received research support by Cognito Therapeutics, a spin-off of MIT. U.P. received paid speakership from neuroCare Group and has a private practice with neuroCare Group, Munich, Germany. C.F., M.M., C.B., M.J.B., E.P., A.S., M.F.S.C. and J.B. report no disclosures. 


\section{References}

[1] Brunoni AR, Amadera J, Berbel B, Volz MS, Rizzerio BG, Fregni F. A systematic review on reporting and assessment of adverse effects associated with transcranial direct current stimulation. Int J Neuropsychopharmacol 2011;14:1133-45. doi:10.1017/S1461145710001690.

[2] Woods AJ, Antal A, Bikson M, Boggio PS, Brunoni AR, Celnik P, et al. A technical guide to tDCS, and related non-invasive brain stimulation tools. Clin Neurophysiol 2016;127:103148. doi:10.1016/j.clinph.2015.11.012.

[3] Bikson M, Brunoni AR, Charvet LE, Clark VP, Cohen LG, Deng Z-D, et al. Rigor and reproducibility in research with transcranial electrical stimulation: An NIMH-sponsored workshop. Brain Stimulat 2017. doi:10.1016/j.brs.2017.12.008.

[4] Boutron I, Guittet L, Estellat C, Moher D, Hróbjartsson A, Ravaud P. Reporting Methods of Blinding in Randomized Trials Assessing Nonpharmacological Treatments. PLoS Med 2007;4:e61. doi:10.1371/journal.pmed.0040061.

[5] Alonzo A, Aaronson S, Bikson M, Husain M, Lisanby S, Martin D, et al. Study design and methodology for a multicentre, randomised controlled trial of transcranial direct current stimulation as a treatment for unipolar and bipolar depression. Contemp Clin Trials 2016;51:65-71. doi:10.1016/j.cct.2016.10.002.

[6] Razza LB, Moffa AH, Moreno ML, Carvalho AF, Padberg F, Fregni F, et al. A systematic review and meta-analysis on placebo response to repetitive transcranial magnetic stimulation for depression trials. Prog Neuropsychopharmacol Biol Psychiatry 2018;81:105-13. doi:10.1016/j.pnpbp.2017.10.016.

[7] Wood L, Egger M, Gluud LL, Schulz KF, Jüni P, Altman DG, et al. Empirical evidence of bias in treatment effect estimates in controlled trials with different interventions and outcomes: meta-epidemiological study. BMJ 2008;336:601-5. doi:10.1136/bmj.39465.451748.AD.

[8] Kessler SK, Turkeltaub PE, Benson JG, Hamilton RH. Differences in the experience of active and sham transcranial direct current stimulation. Brain Stimulat 2012;5:155-62. doi:10.1016/j.brs.2011.02.007.

[9] Brunoni AR, Schestatsky P, Lotufo PA, Benseñor IM, Fregni F. Comparison of blinding effectiveness between sham tDCS and placebo sertraline in a 6-week major depression randomized clinical trial. Clin Neurophysiol 2014;125:298-305.

[10] Wallace D, Cooper NR, Paulmann S, Fitzgerald PB, Russo R. Perceived Comfort and Blinding Efficacy in Randomised Sham-Controlled Transcranial Direct Current Stimulation (tDCS) Trials at $2 \mathrm{~mA}$ in Young and Older Healthy Adults. PLOS ONE 2016;11:e0149703. doi:10.1371/journal.pone.0149703.

[11] Dagan M, Herman T, Harrison R, Zhou J, Giladi N, Ruffini G, et al. Multitarget transcranial direct current stimulation for freezing of gait in Parkinson's disease: Multitarget tDCS for freezing of gait in PD. Mov Disord 2018;33:642-6. doi:10.1002/mds.27300.

[12] Richardson JD, Fillmore P, Datta A, Truong D, Bikson M, Fridriksson J. Toward development of sham protocols for high-definition transcranial direct current stimulation (HD-tDCS). NeuroRegulation 2014;1:62.

[13] Ruffini G, Fox MD, Ripolles O, Miranda PC, Pascual-Leone A. Optimization of multifocal transcranial current stimulation for weighted cortical pattern targeting from realistic 
modeling of electric fields. NeuroImage 2014;89:216-25.

doi:10.1016/j.neuroimage.2013.12.002.

[14] McFadden JL, Borckardt JJ, George MS, Beam W. Reducing procedural pain and discomfort associated with transcranial direct current stimulation. Brain Stimulat 2011;4:38-42. doi:10.1016/j.brs.2010.05.002.

[15] Guarienti F, Caumo W, Shiozawa P, Cordeiro Q, Boggio PS, Benseñor IM, et al. Reducing Transcranial Direct Current Stimulation-Induced Erythema With Skin Pretreatment: Considerations for Sham-Controlled Clinical Trials: Ketoprofen 2\% in tDCS-Induced Erythema. Neuromodulation Technol Neural Interface 2015;18:261-5. doi:10.1111/ner.12230.

[16] Bikson M, Paneri B, Mourdoukoutas A, Esmaeilpour Z, Badran BW, Azzam R, et al. Limited output transcranial electrical stimulation (LOTES-2017): Engineering principles, regulatory statutes, and industry standards for wellness, over-the-counter, or prescription devices with low risk. Brain Stimulat 2018;11:134-57.

[17] Ezquerro F, Moffa AH, Bikson M, Khadka N, Aparicio LVM, Sampaio-Junior B de, et al. The Influence of Skin Redness on Blinding in Transcranial Direct Current Stimulation Studies: A Crossover Trial: ERYTHEMA AND tDCS BLINDING. Neuromodulation Technol Neural Interface 2016. doi:10.1111/ner.12527.

[18] Antal A, Alekseichuk I, Bikson M, Brockmöller J, Brunoni AR, Chen R, et al. Low intensity transcranial electric stimulation: Safety, ethical, legal regulatory and application guidelines. Clin Neurophysiol 2017;128:1774-809. doi:10.1016/j.clinph.2017.06.001.

[19] Fertonani A, Ferrari C, Miniussi C. What do you feel if I apply transcranial electric stimulation? Safety, sensations and secondary induced effects. Clin Neurophysiol 2015;126:2181-8. doi:10.1016/j.clinph.2015.03.015.

[20] Huey ED, Probasco JC, Moll J, Stocking J, Ko M-H, Grafman J, et al. No effect of DC brain polarization on verbal fluency in patients with advanced frontotemporal dementia. Clin Neurophysiol 2007;118:1417-8.

[21] Axelrod V, Rees G, Lavidor M, Bar M. Increasing propensity to mind-wander with transcranial direct current stimulation. Proc Natl Acad Sci 2015;112:3314-9.

[22] Lefaucheur J-P, Antal A, Ayache SS, Benninger DH, Brunelin J, Cogiamanian F, et al. Evidence-based guidelines on the therapeutic use of transcranial direct current stimulation (tDCS). Clin Neurophysiol 2017;128:56-92. doi:10.1016/j.clinph.2016.10.087.

[23] Nitsche MA, Cohen LG, Wassermann EM, Priori A, Lang N, Antal A, et al. Transcranial direct current stimulation: State of the art 2008. Brain Stimulat 2008;1:206-23. doi:10.1016/j.brs.2008.06.004.

[24] Priori A, Berardelli A, Rona S, Accornero N, Manfredi M. Polarization of the human motor cortex through the scalp. Neuroreport 1998;9:2257-60.

[25] Antal A, Polania R, Schmidt-Samoa C, Dechent P, Paulus W. Transcranial direct current stimulation over the primary motor cortex during fMRI. NeuroImage 2011;55:590-6. doi:10.1016/j.neuroimage.2010.11.085.

[26] Kuo M-F, Paulus W, Nitsche MA. Sex differences in cortical neuroplasticity in humans. Neuroreport 2006;17:1703-7. doi:10.1097/01.wnr.0000239955.68319.c2.

[27] Furubayashi T, Terao Y, Arai N, Okabe S, Mochizuki H, Hanajima R, et al. Short and long duration transcranial direct current stimulation (tDCS) over the human hand motor area. Exp Brain Res 2008;185:279-86. doi:10.1007/s00221-007-1149-Z. 
[28] Javadi AH, Cheng P, Walsh V. Short duration transcranial direct current stimulation (tDCS) modulates verbal memory. Brain Stimulat 2012;5:468-74. doi:10.1016/j.brs.2011.08.003.

[29] Nitsche MA, Paulus W. Excitability changes induced in the human motor cortex by weak transcranial direct current stimulation. J Physiol 2000;527:633-9. doi:10.1111/j.14697793.2000.t01-1-00633.x.

[30] Peña-Gómez C, Sala-Lonch R, Junqué C, Clemente IC, Vidal D, Bargalló N, et al. Modulation of large-scale brain networks by transcranial direct current stimulation evidenced by resting-state functional MRI. Brain Stimulat 2012;5:252-63. doi:10.1016/j.brs.2011.08.006.

[31] Stagg CJ, Lin RL, Mezue M, Segerdahl A, Kong Y, Xie J, et al. Widespread Modulation of Cerebral Perfusion Induced during and after Transcranial Direct Current Stimulation Applied to the Left Dorsolateral Prefrontal Cortex. J Neurosci 2013;33:11425-31. doi:10.1523/JNEUROSCI.3887-12.2013.

[32] Dyke K, Kim S, Jackson GM, Jackson SR. Intra-Subject Consistency and Reliability of Response Following $2 \mathrm{~mA}$ Transcranial Direct Current Stimulation. Brain Stimulat 2016;9:819-25. doi:10.1016/j.brs.2016.06.052.

[33] Nikolin S, Martin D, Loo CK, Boonstra TW. Effects of TDCS dosage on working memory in healthy participants. Brain Stimulat 2018. doi:10.1016/j.brs.2018.01.003.

[34] Boonstra TW, Nikolin S, Meisener A-C, Martin DM, Loo CK. Change in Mean Frequency of Resting-State Electroencephalography after Transcranial Direct Current Stimulation. Front Hum Neurosci 2016;10:270. doi:10.3389/fnhum.2016.00270.

[35] Creutzfeldt OD, Fromm GH, Kapp H. Influence of transcortical dc currents on cortical neuronal activity. Exp Neurol 1962;5:436-452.

[36] Reato D, Rahman A, Bikson M, Parra LC. Low-Intensity Electrical Stimulation Affects Network Dynamics by Modulating Population Rate and Spike Timing. J Neurosci 2010;30:15067-79. doi:10.1523/JNEUROSCI.2059-10.2010.

[37] Francis JT, Gluckman BJ, Schiff SJ. Sensitivity of neurons to weak electric fields. J Neurosci Off J Soc Neurosci 2003;23:7255-61.

[38] Martiny K, Lunde M, Bech P. Transcranial Low Voltage Pulsed Electromagnetic Fields in Patients with Treatment-Resistant Depression. Biol Psychiatry 2010;68:163-9. doi:10.1016/j.biopsych.2010.02.017.

[39] Leuchter AF, Cook IA, Feifel D, Goethe JW, Husain M, Carpenter LL, et al. Efficacy and Safety of Low-field Synchronized Transcranial Magnetic Stimulation (sTMS) for Treatment of Major Depression. Brain Stimulat 2015;8:787-94. doi:10.1016/j.brs.2015.05.005.

[40] Schwarzkopf DS, Silvanto J, Rees G. Stochastic Resonance Effects Reveal the Neural Mechanisms of Transcranial Magnetic Stimulation. J Neurosci 2011;31:3143-7. doi:10.1523/JNEUROSCI.4863-10.2011.

[41] Brunoni AR, Moffa AH, Sampaio-Junior B, Borrione L, Moreno ML, Fernandes RA, et al. Trial of Electrical Direct-Current Therapy versus Escitalopram for Depression. N Engl J Med 2017;376:2523-33. doi:10.1056/NEJMoa1612999.

[42] Pavlova EL, Menshikova AA, Semenov RV, Bocharnikova EN, Gotovtseva GN, Druzhkova TA, et al. Transcranial direct current stimulation of 20- and 30-minutes combined with sertraline for the treatment of depression. Prog Neuropsychopharmacol Biol Psychiatry 2018;82:31-8. doi:10.1016/j.pnpbp.2017.12.004. 
[43] Sampaio-Junior B, Tortella G, Borrione L, Moffa AH, Machado-Vieira R, Cretaz E, et al. Efficacy and Safety of Transcranial Direct Current Stimulation as an Add-on Treatment for Bipolar Depression: A Randomized Clinical Trial. JAMA Psychiatry 2018;75:158. doi:10.1001/jamapsychiatry.2017.4040.

[44] Loo CK, Husain MM, McDonald WM, Aaronson S, O’Reardon JP, Alonzo A, et al. International randomized-controlled trial of transcranial Direct Current Stimulation in depression. Brain Stimulat 2018;11:125-33. doi:10.1016/j.brs.2017.10.011.

[45] Gandiga PC, Hummel FC, Cohen LG. Transcranial DC stimulation (tDCS): A tool for double-blind sham-controlled clinical studies in brain stimulation. Clin Neurophysiol 2006;117:845-50. doi:10.1016/j.clinph.2005.12.003.

[46] Palm U, Reisinger E, Keeser D, Kuo M-F, Pogarell O, Leicht G, et al. Evaluation of Sham Transcranial Direct Current Stimulation for Randomized, Placebo-Controlled Clinical Trials. Brain Stimulat 2013;6:690-5. doi:10.1016/j.brs.2013.01.005.

[47] Wörsching J, Padberg F, Ertl-Wagner B, Kumpf U, Kirsch B, Keeser D. Imaging transcranial direct current stimulation (tDCS) of the prefrontal cortex - correlation or causality in stimulation-mediated effects? Neurosci Biobehav Rev 2016;69:333-56. doi:10.1016/j.neubiorev.2016.08.001.

[48] Lefaucheur J-P. A comprehensive database of published tDCS clinical trials (2005-2016). Neurophysiol Clin Neurophysiol 2016;46:319-98. doi:10.1016/j.neucli.2016.10.002.

[49] Margraf J, Ehlers A, Roth WT, Clark DB, Sheikh J, Agras WS, et al. How“ blind” are double-blind studies? J Consult Clin Psychol 1991;59:184.

[50] White K, Kando J, Park T, Waternaux C, Brown WA. Side effects and the "blindability" of clinical drug trials. Am J Psychiatry 1992.

[51] Quitkin FM. Placebos, drug effects, and study design: a clinician's guide. Am J Psychiatry 1999;156:829-836.

[52] Moncrieff J. A comparison of antidepressant trials using active and inert placebos. Int $\mathbf{J}$ Methods Psychiatr Res 2003;12:117-127.

[53] Borckardt JJ, Walker J, Branham RK, Rydin-Gray S, Hunter C, Beeson H, et al. Development and evaluation of a portable sham transcranial magnetic stimulation system. Brain Stimulat 2008;1:52-9. doi:10.1016/j.brs.2007.09.003.

[54] Baethge C, Assall OP, Baldessarini RJ. Systematic Review of Blinding Assessment in Randomized Controlled Trials in Schizophrenia and Affective Disorders 2000-2010. Psychother Psychosom 2013;82:152-60. doi:10.1159/000346144.

[55] Davidson RJ, Kaszniak AW. Conceptual and methodological issues in research on mindfulness and meditation. Am Psychol 2015;70:581-92. doi:10.1037/a0039512.

[56] Patterson B, Boyle MH, Kivlenieks M, Van Ameringen M. The use of waitlists as control conditions in anxiety disorders research. J Psychiatr Res 2016;83:112-20. doi:10.1016/j.jpsychires.2016.08.015.

[57] Benedetti F. Placebo Effects: From the Neurobiological Paradigm to Translational Implications. Neuron 2014;84:623-37. doi:10.1016/j.neuron.2014.10.023.

[58] Kaptchuk TJ, Goldman P, Stone DA, Stason WB. Do medical devices have enhanced placebo effects? J Clin Epidemiol 2000;53:786-792.

[59] Kaptchuk TJ, Miller FG. Placebo effects in medicine. N Engl J Med 2015;373:8-9.

[60] Burke MJ, Kaptchuk TJ, Pascual-Leone A. Challenges of Differential Placebo Effects in Contemporary Medicine: The Example of Brain Stimulation: Differential Placebo Effects and Brain Stimulation. Ann Neurol 2018. doi:10.1002/ana.25387. 
[61] Rochas V, Gelmini L, Krolak-Salmon P, Poulet E, Saoud M, Brunelin J, et al. Disrupting Pre-SMA Activity Impairs Facial Happiness Recognition: An Event-Related TMS Study. Cereb Cortex 2013;23:1517-25. doi:10.1093/cercor/bhs133.

[62] Kober SE, Witte M, Grinschgl S, Neuper C, Wood G. Placebo hampers ability to selfregulate brain activity: A double-blind sham-controlled neurofeedback study. NeuroImage 2018;181:797-806. doi:10.1016/j.neuroimage.2018.07.025.

[63] Wörsching J, Padberg F, Goerigk S, Heinz I, Bauer C, Plewnia C, et al. Testing assumptions on prefrontal transcranial direct current stimulation: Comparison of electrode montages using multimodal fMRI. Brain Stimulat 2018.

[64] Fonteneau C, Redoute J, Haesebaert F, Le Bars D, Costes N, Suaud-Chagny M-F, et al. Frontal Transcranial Direct Current Stimulation Induces Dopamine Release in the Ventral Striatum in Human. Cereb Cortex 2018;28:2636-46.

[65] Horvath JC, Forte JD, Carter O. Evidence that transcranial direct current stimulation (tDCS) generates little-to-no reliable neurophysiologic effect beyond MEP amplitude modulation in healthy human subjects: A systematic review. Neuropsychologia 2015;66:213-36. doi:10.1016/j.neuropsychologia.2014.11.021.

[66] Antal A, Keeser D, Priori A, Padberg F, Nitsche MA. Conceptual and Procedural Shortcomings of the Systematic Review "Evidence That Transcranial Direct Current Stimulation (tDCS) Generates Little-to-no Reliable Neurophysiologic Effect Beyond MEP Amplitude Modulation in Healthy Human Subjects: A Systematic Review" by Horvath and Co-workers. Brain Stimulat 2015;8:846-9. doi:10.1016/j.brs.2015.05.010.

[67] Peterchev AV, Wagner TA, Miranda PC, Nitsche MA, Paulus W, Lisanby SH, et al. Fundamentals of transcranial electric and magnetic stimulation dose: Definition, selection, and reporting practices. Brain Stimulat 2012;5:435-53. doi:10.1016/j.brs.2011.10.001.

[68] Dissanayaka TD, Zoghi M, Farrell M, Egan GF, Jaberzadeh S. Sham transcranial electrical stimulation and its effects on corticospinal excitability: a systematic review and metaanalysis. Rev Neurosci 2018;29:223-32. doi:10.1515/revneuro-2017-0026. 


\section{Figure captions}

Figure 1 - Illustration of different sham protocols used in tDCS studies - A) Original Gandiga sham protocol: 10s ramp-up, 30s stimulation, turn off the stimulator. B) Adapted tDCS protocols: The stimulation period is the same for both active and sham interventions. Depending on studies, sham tDCS consists in either 1 or 2 ramps per session (beginning, middle orland end) with different duration of ramps (5, 8, 10, 15, $30 \mathrm{~s}$ ). Different durations of active stimulation are delivered at the beginning and/or end of the stimulation period (Duration $_{\text {Sham }}=$ $5,8,10,15,20,30,40,60,120 \mathrm{~s})$. The period of active stimulation reaches the same or reduced peak intensity compared to the intensity delivered in the active intervention. Lastly, some studies report a constant low intensity stimulation (0.016 or $0.034 \mathrm{~mA})[33,44]$.

Table 1 - Main parameters of the different built-in-sham modes from commonly used commercial stimulators, as described in their manuals. Constant intensity for each stimulator was reported for the current available devices. It should be kept in mind that analogue electronic of the current source could have a 'noise' of equal or below 0.010mA. Y=Yes; N=No

Supplementary Material 1 - Sham controlled-studies using bifrontal (F3/F4/FP1/FP2) and fronto-temporal montages (F3FP1/T3P3), including the details of the sham parameters, primary outcome and effect reported when comparing the active arm to the sham arm.

Supplementary Material 2 - Boxplot exploring the difference in the total charge delivered in the sham arm depending on the effect on the primary outcome of the study, when comparing the active arm and sham arm. $Y=Y e s ; N=N o$ 
$\Delta$ Intensity (mA)
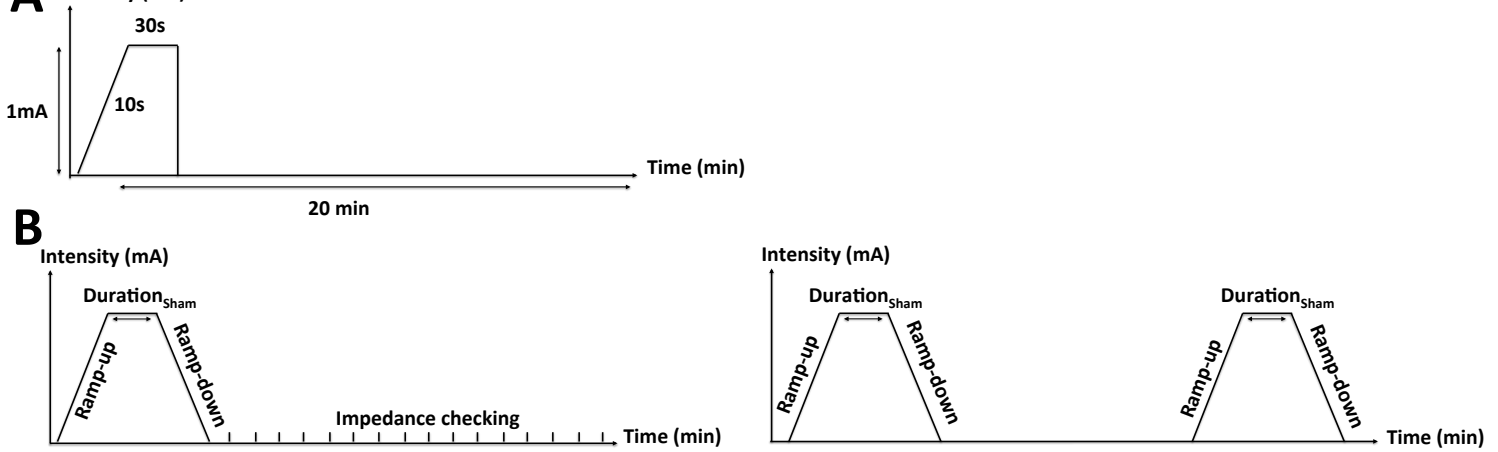

\section{Intensity (mA)}

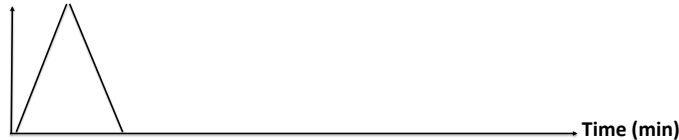

Intensity (mA)
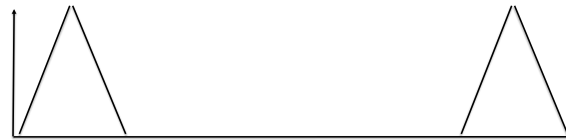

Time (min)

Intensity (mA)

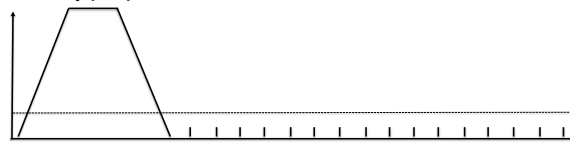

Constant Low Intensity Time ( $\mathrm{min}$ )

\section{Intensity (mA)}

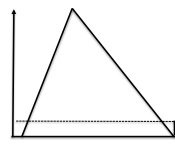

Constant Low Intensity Time (min) 


\begin{tabular}{|c|c|c|c|c|}
\hline & $\begin{array}{c}\text { neuroConn } \\
\text { (Illmenau, } \\
\text { Germany) } \\
\end{array}$ & $\begin{array}{c}\text { Soterix } \\
\text { Medical Inc } \\
(\text { New York, USA }) \\
\end{array}$ & $\begin{array}{c}\text { Neuroelectrics } \\
\text { Starstim } \\
\text { (Barcelona, Spain) } \\
\end{array}$ & $\begin{array}{c}\text { Sooma } \\
(\text { Helsinki, Finland })\end{array}$ \\
\hline Duration $_{\text {Sham }}(\mathrm{s})$ & $\operatorname{Duration}_{\text {Active }}(\mathrm{s}) / 30$ & Programmable & Programmable & None \\
\hline $\begin{array}{l}\text { Peak intensity } \\
\qquad(\mathrm{mA})\end{array}$ & $\begin{array}{c}\text { Same as in active } \\
\text { condition }\end{array}$ & Programmable & $\begin{array}{c}\text { Same as in active } \\
\text { condition }\end{array}$ & $\begin{array}{c}\text { Same as in active } \\
\text { condition }\end{array}$ \\
\hline $\begin{array}{c}\text { Constant intensity } \\
\qquad(\mathrm{mA})\end{array}$ & $+/-0.010$ & 0.012 to 0.024 & $<0.010$ & 0.3 \\
\hline $\begin{array}{l}\text { Number of ramp } \\
\text { up/down periods }\end{array}$ & $\begin{array}{c}1 \\
\text { (beginning) }\end{array}$ & Programmable & $\begin{array}{c}1 \text { or } 2 \\
\left(2^{\text {nd }} \text { optionally at }\right. \\
\text { the end })\end{array}$ & $\begin{array}{c}1 \\
\text { (beginning) }\end{array}$ \\
\hline $\begin{array}{l}\text { Ramp up/ } \\
\text { Ramp down } \\
\text { duration }\end{array}$ & Same as active & Programmable & Programmable & $0.1 \mathrm{~mA} / \mathrm{s}$ \\
\hline Impedance check & $\begin{array}{c}\text { Brief pulses of } 110 \\
\mu \mathrm{A} \text { over } 15 \mathrm{~ms} \\
\text { every } 550 \mathrm{~ms}\end{array}$ & Emulated & Fake impedance & $\begin{array}{c}\text { Continuous current } \\
0.3 \mathrm{~mA}\end{array}$ \\
\hline $\begin{array}{c}\text { Single / } \\
\text { Double blind mode }\end{array}$ & $\begin{array}{l}\mathrm{Y} / \\
\mathrm{Y}\end{array}$ & $\begin{array}{l}\mathrm{Y} / \\
\mathrm{Y}\end{array}$ & $\begin{array}{l}\mathrm{Y} / \\
\mathrm{Y}\end{array}$ & $\begin{array}{l}\mathrm{Y} / \\
\mathrm{Y}\end{array}$ \\
\hline $\begin{array}{c}\text { Example } \\
\text { Active stimulation } \\
\text { of } 20 \mathrm{~min} \text { at } 1 \mathrm{~mA} \text {, } \\
\text { 30s ramps }\end{array}$ & $\begin{array}{l}30 \mathrm{~s} \text { ramp up, } 1 \\
\mathrm{~mA} \text { stimulation } \\
\text { during } 40 \mathrm{~s}, 30 \mathrm{~s} \\
\text { ramp down } \\
=1 \mathrm{~min} 40 \mathrm{~s} \\
\text { stimulation } \\
=70 \mathrm{mC}+ \\
\text { impedance check } \\
(3.48 \mathrm{mC})\end{array}$ & $\begin{array}{l}(30 \mathrm{~s} \text { ramp up to } 1 \\
\mathrm{mA}, 30 \mathrm{~s} \text { ramp } \\
\text { down })_{\text {beginning }+ \text { end }} \\
=2 \mathrm{~min} \\
\text { stimulation } \\
=60 \mathrm{mC}\end{array}$ & $\begin{array}{l}\text { (30 s ramp up to } 1 \\
\mathrm{~mA}, 30 \mathrm{~s} \text { ramp } \\
\text { down })_{\text {beginning }+ \text { end }} \\
\text { optional } \\
=1 \text { or } 2 \mathrm{~min} \\
\text { stimulation } \\
=30 \text { or } 60 \mathrm{mC}\end{array}$ & $\begin{array}{l}10 \mathrm{~s} \text { ramp up to } 1 \\
\mathrm{~mA}, 7 \mathrm{~s} \text { ramp } \\
\text { down to } 0.3 \mathrm{~mA} \\
\text { for } 20 \mathrm{~min}, 3 \mathrm{~s} \\
\text { ramp-down at the } \\
\text { end } \\
=20 \mathrm{~min} \\
\text { stimulation } \\
=370 \mathrm{mC}\end{array}$ \\
\hline
\end{tabular}

